\title{
COMMENTARY
}

\section{Drotrecogin alfa (activated) ... a sad final fizzle to a roller-coaster party}

\author{
Derek C Angus*
}

Following the failure of PROWESS-SHOCK to demonstrate efficacy, Eli Lilly and Company withdrew drotrecogin alfa (activated) from the worldwide market. Drotrecogin was initially approved after the original trial, PROWESS, was stopped early for overwhelming efficacy. These events prompt consideration of both the initial approval decision and the later decision to withdraw. It is regrettable that the initial decision was made largely on a single trial that was stopped early. However, the decision to approve was within the bounds of normal regulatory practice and was made by many approval bodies around the world. Furthermore, the overall withdrawal rate of approved drugs remains very low. The decision to withdraw was a voluntary decision by Eli Lilly and Company and likely reflected key business considerations. Drotrecogin does have important biologic effects, and it is probable that we do not know how best to select patients who would benefit. Overall, there may still be a small advantage to drotrecogin alfa, even used nonselectively, but the costs of determining such an effect with adequate certainty are likely prohibitive, and the point is now moot. In the future, we should consider ways to make clinical trials easier and quicker so that more information can be available in a timely manner when considering regulatory approval. At the same time, more sophisticated selection of patients seems key if we are to most wisely test agents designed to manipulate the septic host response.

With the announcement on 26 October 2011 that Eli Lilly and Company (Indianapolis, IN, USA) was withdrawing drotrecogin alfa (activated) from the worldwide market, we witnessed the end of the only drug specifically approved for sepsis. The move was prompted by the

*Correspondence: angusdc@upmc.edu

Department of Critical Care Medicine, University of Pittsburgh, 614 Scaife Hall, 3550 Terrace Street, Pittsburgh, PA 15261, USA failure of PROWESS-SHOCK, a large international study, to confirm the benefit reported from the original trial, PROWESS (Protein C Worldwide Evaluation in Severe Sepsis), 10 years ago. In the aftermath, many questions will be raised. Here, I discuss two initial questions. Before proceeding, I should declare that I led the long-term follow-up and cost-effectiveness studies accompanying PROWESS and served on the Data Safety and Monitoring Board of PROWESS-SHOCK (see Acknowledgments for full disclosure).

\section{First, was the initial decision to approve drotrecogin wrong?}

Drotrecogin was approved largely on the basis of a single phase 3 trial, which was stopped early for efficacy [1]. Most drugs are approved after two positive phase 3 trials, but exceptions are made when there are impressive supporting data, there is a compelling unmet clinical need, or the trial results are particularly impressive. Although an external US Food and Drug Administration (FDA) advisory panel was split on whether to approve, the FDA nevertheless felt that these conditions were met. Many of the world's large drug regulatory bodies concurred with the FDA decision. It seems, therefore, that the decision to approve, though based on only one phase 3 trial, was consistent with the procedures and habits of regulatory bodies around the world.

For all new drugs, approval occurs at a point when considerable uncertainty remains. Typically, the drug has been administered to only a few thousand patients, in highly controlled situations, with limited long-term follow-up. The rationale for not waiting until more is known about a drug is twofold. First, further delay means that patients are denied new and effective therapies. Second, a longer time to generate more evidence raises the drug development costs for pharmaceutical companies while shortening the post-approval patent life (when a company recoups its investment), thus worsening the risk-reward ratio and potentially choking overall investment in drug development.

Because approval occurs while uncertainty persists, a variety of post-approval surveillance activities are performed in case the decision must be reversed. In the 
five years leading up to drotrecogin's approval in 2001, the FDA approved 597 new therapies. Of these, 1.7\% have subsequently been withdrawn [2-4]. In other words, there is a low, but non-zero, rate of drug withdrawal. A lower rate would be preferable, but without major changes to patent laws or to the science and costs of drug development, the chilling effect of a more stringent approval process on dwindling drug pipelines would likely be considered intolerable.

So, while we might lament that a sepsis drug was one of the unlucky ones, the fundamental drug approval process that led to drotrecogin approval does not seem too lenient, wrong, or unreasonable. That said, it is a shame that PROWESS was stopped early, something outside the control of the FDA, as early stopping biases toward an overestimate of treatment effect [5]. And it is a shame that the costs and logistics of running two concurrent phase 3 trials in critical care seem to be insurmountable obstacles in the drug development process. Cheaper and easier trials could allow us to generate greater certainty without compromising drug pipeline.

\section{Second, was the decision to withdraw drotrecogin too hasty?}

The usual reason for withdrawal is determination of a previously unknown yet highly undesired side effect. Post-approval surveillance of drotrecogin included some large observational studies. These studies generally reported mortality benefits similar to that seen in PROWESS [612]. The studies also provided greater information about bleeding risks, which led to further label restrictions [13]. However, somewhat unusually, the withdrawal in this instance was a voluntary decision based not on safety but on failure to confirm efficacy.

Drotrecogin is a biologically active agent. Numerous human and animal studies suggest that it modulates coagulation and inflammatory pathways and interacts with endothelial function in the midst of intense innate immune responses to challenges such as sepsis. It is certainly conceivable that such effects could hurt or help patients with sepsis. A previous simulation exercise of theoretical anti-tumor necrosis factor (anti-TNF) antibody trials in sepsis demonstrated that modest differences in the distribution of unmeasured variables such as host genotype and pathogen characteristics could lead to trials in which the same drug produces opposing results, even when patients meet the same clinical criteria [14]. It seems plausible that the same could be true with drotrecogin.

PROWESS-SHOCK attempted to enroll patients ideally suited for drotrecogin. In the original PROWESS study, the largest reduction in absolute mortality was noted in patients who appeared to be sicker (for example, those presenting with septic shock). A subsequent trial
- Administration of Drotrecogin Alfa (Activated) in Early Stage Severe Sepsis, or ADDRESS - targeted patients with lower severity of illness and could not demonstrate efficacy [15]. Thus, we now have an original trial suggesting benefit in both low and high severity risk, with a constant relative risk reduction but variable absolute reduction, and two subsequent trials mimicking the low and high ends of the original trial but failed to repeat the positive findings. Provided that all trials were conducted well, the results of PROWESS-SHOCK and ADDRESS raise doubt about the PROWESS results, but, equally, the PROWESS results raise doubt about those of PROWESSSHOCK and ADDRESS.

When data from multiple trials are synthesized, such as in a meta-analysis, a negative study does not trump a positive study of similar quality. Rather, the results from both trials are combined to give an overall estimate of treatment effect. Given the potential for differences in important but unmeasured variables at baseline in sepsis to change the result, such an approach seems wise. We have not yet seen such a meta-analysis. However, it seems possible that the result will be a point estimate in favor of drotrecogin over placebo but of a magnitude far smaller than in the original trial and probably no longer statistically significant.

If that is the case, things get tricky. If the combined estimate from the literature is, say, a non-significant $2 \%$ to $3 \%$ reduction in mortality, would we be interested in confirming whether such an effect was significant? That would normally depend on the cost of one more (much larger) confirmatory trial, our desire to tolerate non-fatal bleeding side effects, and the resulting financial impact (both per-patient cost-effectiveness and global increase in spending) of adopting the drug should the benefit be confirmed.

Such quandaries could be formally estimated in a value-of-information analysis - how valuable is it to know the answer with greater certainty? However, the decision was taken out of our hands. Eli Lilly and Company no doubt considered the potentially very large cost of another trial, the fact that regulatory agencies and the field of critical care might be so skeptical as to threaten the ability to conduct another trial or adopt its results into practice or both, and the likelihood that the trial would be negative. Taking these factors together, the company presumably decided that to go forward was just too risky. Whether the action of Eli Lilly and Company has left a drug that could cut sepsis mortality by $2 \%$ to $3 \%$ 'on the table' is something we will now likely never know.

\section{Next steps}

We will all see the details of PROWESS-SHOCK published in the coming weeks or months. No doubt, a formal meta-analysis will follow. Residual issues to 
consider will likely be as follows. First, should this story reinvigorate our drive to complement clinical enrollment criteria with biomarkers that better select patients likely to benefit from a given immunomodulating agent?

Second, should we ask of ourselves what we as a community might have done differently? Certainly, greater engagement in clinical trials would seem to be an obvious first step - a huge part of the costs of clinical trials is that they take a long time and enroll only a tiny fraction of all patients with severe sepsis. Our ability to make wiser choices about drugs would be enhanced if we could conduct larger trials more rapidly. Much time, energy, and emotion were devoted to forming opinions about PROWESS and about drotrecogin, often with strongly voiced opinions about both the drug and Eli Lilly and Company. One can hope that decisions about future drugs will be made in environments richer in data and poorer in opinion.

Finally, intensivists do not develop drugs. If we believe that there is a role for pharmacomanipulation of critical illness, our partnership with the pharmaceutical industry is a prerequisite. Thus, we must think about whether the partnership works properly in terms of open, efficient, rapid, and rigorous science for the optimal benefit of all concerned, especially our patients.

\section{Abbreviations}

ADDRESS, Administration of Drotrecogin Alfa (Activated) in Early Stage Severe Sepsis; FDA, US Food and Drug Administration; PROWESS, Protein C Worldwide Evaluation in Severe Sepsis.

\section{Competing interests}

The author declares that he was principal investigator on grants received by the University of Pittsburgh from Eli Lilly and Company for the conduct of the long-term follow-up and cost-effectiveness studies accompanying PROWESS. He also received consulting fees and speaking honoraria from Eli Lilly and Company between 1996 and 2004. He received compensation from Eli Lilly and Company for serving on the Data Safety and Monitoring Board for PROWESS-SHOCK. He has also received consulting fees from Eisai Inc. (Woodcliff Lake, NJ, USA) and Idaho Technology Inc. (Salt Lake City, UT, USA), which are also engaged in sepsis research.

\section{Acknowledgments}

The author gratefully acknowledges Shamly Austin for her assistance generating data on FDA approval and withdrawal rates discussed in this article.

Published: 6 February 2012

\section{References}

1. Bernard GR, Vincent J-L, Laterre P-F, LaRosa SP, Dhainaut JF, Lopez-Rodriguez A, Steingrub JS, Garber GE, Helterbrand JD, Ely EW, Fisher CJ: Efficacy and safety of recombinant human activated protein $\mathrm{C}$ for severe sepsis. N Engl
J Med 2001, 344:699-709.

2. CenterWatch: FDA-approved drugs. Drug information [http://www. centerwatch.com/drug-information/fda-approvals/default. aspx?DrugYear=1997].

3. US Food and Drug Administration: Drug approval reports. FDA approved drug products [http://www.accessdata.fda.gov/scripts/cder/drugsatfda/ index.cfm?fuseaction=Reports.ReportsMenu].

4. US Government Accountability Office: Drugs Safety: Most Drugs Withdrawn in Recent Years Had Greater Health Risks in Women. Washington, DC: US Government Accountability Office; 2001

5. Bassler D, Briel M, Montori VM, LaRosa SP, Dhainaut JF, Lopez-Rodriguez A, Steingrub JS, Garber GE, Helterbrand JD, Ely EW, Fisher CJ, Lane M, Glasziou P Zhou Q, Heels-Ansdell D, Walter SD, Guyatt GH, Flynn DN, Elamin MB, Murad MH, Abu Elnour NO, Lampropulos JF, Sood A, Mullan RJ, Erwin PJ, Bankhead CR, Perera R, Ruiz Culebro C, You JJ, Mulla SM, et al:: Stopping randomized trials early for benefit and estimation of treatment effects: systematic review and meta-regression analysis. JAMA 2010, 303:1180-1187.

6. Levy MM, Dellinger RP, Townsend SR, Linde-Zwirble WT, Marshall JC, Bion J, Schorr C, Artigas A, Ramsay G, Beale R, Parker, MM, Gerlach H, Reinhart K, Silva E, Harvey M, Regan S, Angus DC: The Surviving Sepsis Campaign: results of an international guideline-based performance improvement program targeting severe sepsis. Crit Care Med 2010, 38:367-374.

7. Lindenauer PK, Rothberg MB, Nathanson BH, Pekow PS, Steingrub JS: Activated protein $C$ and hospital mortality in septic shock: a propensitymatched analysis. Crit Care Med 2010, 38:1101-1107.

8. Martin G, Brunkhorst FM, Janes JM, Reinhart K, Sundin DP, Garnett K, Beale R: The international PROGRESS registry of patients with severe sepsis: drotrecogin alfa (activated) use and patient outcomes. Crit Care 2009, 13:R103

9. Pestana D, Espinosa E, Sanguesa-Molina JR, Ramos R, Perez-Fernandez E, Duque M, Martinez-Casanova E: Compliance with a sepsis bundle and its effect on intensive care unit mortality in surgical septic shock patients. J Trauma 2010, 69:1282-1287.

10. Ridley S, Lwin A, Wyncoll D, Lippett S, Watson D, Gunning K, Higgins D: Drotrecogin alfa (activated): diffusion from clinical trials to clinical practice. Eur J Anaesthesiol 2008, 25:211-216.

11. Vincent JL, Bernard GR, Beale R, Doig C, Putensen C, Dhainaut JF, Artigas A, Fumagalli R, Macias W, Wright T, Wong K, Sundin DP, Turlo MA: Drotrecogin alfa (activated) treatment in severe sepsis from the global open-label trial ENHANCE: further evidence for survival and safety and implications for early treatment. Crit Care Med 2005, 33:2266-2277.

12. Vincent JL, Laterre PF, Decruyenaere J, Spapen H, Raemaekers J, Damas F, Rogiers P, Sartral M, Haentjens T, Nelson D, Janes J: A registry of patients treated with drotrecogin alfa (activated) in Belgian intensive care units an observational study. Acta Clin Belg 2008, 63:25-30.

13. US Food and Drug Administration: Drug safety labeling changes [http://www.fda.gov/Safety/MedWatch/Safetylnformation/SafetyRelatedDrugLabelingChanges/default.htm].

14. Clermont G, Bartels J, Kumar R, Constantine G, Vodovotz Y, Chow C: In silico design of clinical trials: a method coming of age. Crit Care Med 2004 32:2061-2070

15. Abraham E, Laterre PF, Garg R, Levy H, Talwar D, Trzaskoma BL, Francois B, Guy JS, Bruckmann M, Rea-Neto A, Rossaint R, Perrotin D, Sablotzki A, Arkins N, Utterback BG, Macias WL: Drotrecogin alfa (activated) for adults with severe sepsis and a low risk of death. N Engl J Med 2005, 353:1332-1341.

doi:10.1186/cc11152

Cite this article as: Angus DC: Drotrecogin alfa (activated) ... a sad final

fizzle to a roller-coaster party. Critical Care 2012, 16:107. 